JURNAL BASICEDU

Research \& Learning in Elementary Education

https://jbasic.org/index.php/basicedu

\title{
PERBEDAAN MODEL PEMBELAJARAN PROBLEM SOLVING DAN DISCOVERY LEARNING DITINJAU DARI KETERAMPILAN BERPIKIR KRITIS PESERTA DIDIK
}

\author{
Maklonia Meling Moto ${ }^{1}$, Srigiarti ${ }^{2}$ \\ Universitas Negeri Padang, Sumatera Barat, Indonesia ${ }^{1,2}$ \\ E-mail : : $292016148 @$ student.uksw.edu ${ }^{1}$ srigiarty@gmail.com ${ }^{2}$
}

\begin{abstract}
Abstrak
Penelitian ini bertujuan untuk mengetahui perbedaan model pembelajaran Discovery learning dan Problem Solving ditinjau dari keterampilan berpikir kritis peserta didik kelas 4 sekolah Dasar pada pembelajaran tematik. Sampel penelitian diambil menggunakan teknik probality yaitu dengan area sampling atau cluster sampling sehingga jumlah sampel penelitian berjumlah 51 peserta didik. Metode penelitian yang dugunakan adalah eksperimen semu (Quasi Eksperimental Research). Teknik analisis data menggunakan teknik deskriptif dan uji T. hasil penelitian menunjukan bahwa penggunaan model pembelajaran Problem Solving lebih efektif dalam meningkatkan keterampilan berpikir kritis dari pada model pembelajaran Discovery Learning. Hal tersebut dapat dibuktikan dengan hasil akhir yang diperoleh dari kelas eksperimen dengan jumlah peserta didik (N) sebanyak 26 peserta didik dengan nilai rata-rata sebesar 61,32, sementara pada kelas kontol diperoleh nilai rata-rata sebesar 66,85 dengan $(\mathrm{N})$ sebanyak 25 peserta didik. Hasil uji T diperoleh nilai signifikansi pada $\mathrm{F}$ sebesar 2,589 dan nilai sig 0,024 < 0,050, maka Ho ditolak dan Ha diterima yang artinya bahwa terdapat perbedaan yang signifikan dalam penerapan model Problem Solving dan discovery learning ditinjau dari keterampilan berpikir kritis peserta didik kelas 4 SD dalam pembelajaran tematik.
\end{abstract}

Kata Kunci : Problem Solving, discovery learning, keterampilan berpikir kritis

\begin{abstract}
This study aims to determine the differences in Discovery learning and Problem Solving review from the students critical thinking skill of Grade 4 elementary school on thematic learning. Research samples were taken using probality technique which is with sampling area or cluster sampling so the number of research samples amounted to 51 students. The research methods that are used are pseudo experiments (Quasi experimental Research). Data analysis techniques using descriptive techniques and test $\mathrm{T}$. Research results suggest that the use of the Problem Solving learning model is more effective in improving the critical thinking skills of the discovery learning model. This can be proved by the final result obtained from the experimental class with the number of students $(\mathrm{N})$ of 26 learners with an average value of 61.32, while the Dick class obtained an average value of 66.85 with $(\mathrm{N})$ as much as 25 learners. $\mathrm{T}$ test result obtained significance value in $\mathrm{F}$ of 2.589 and the value of sig $0.024<0.050$, then Ho rejected and Ha accepted which means that there is a significant difference in the implementation of the Problem Solving model and Discovery Learning reviewed from the critical thinking skills of Grade 4 learners elementary school in thematic learning
\end{abstract}

Keywords: Problem Solving, discovery learning, critical thinking skills

@ Jurnal Basicedu 2020

$\triangle$ Corresponding author :

Address : -

ISSN 2580-3735 (Media Cetak)

Email : -

ISSN 2580-1147 (Media Online)

Phone :- 
499 Perbedaan model pembelajaran problem solving dan discovery learning ditinjau dari keterampilan berpikir kritis peserta didik - Maklonia Meling Moto, Srigiarti

\section{PENDAHULUAN}

Permendikbud No. 65 Tahun 2013 tentang Standar Proses Pendidikan Dasar dan Menegah, menyatakan bahwa "Sesuai dengan Standar Kopetensi Lulusan dan Standar Isi, prinsip pembelajaran yang digunakan dari pembelajaran persial menjadi pembelajaran yang terpadu". Penerapan kurikulum 2013 ini terjadi perubahan paradigma pembelajaran, dimana peserta didik dilatih untuk belajar mengobservasi, mengajukan pertanyaan, mengumpulkan data, menganalisis data, dan mengkomunikasikan hasil belajar atau dapat disebut juga dengan pendekatan saintifik. Pendekatan saintifik harus dilaksanakan agar kemampuan peserta didik dapat berkembang sehingga peserta didik mampu untuk mandiri dan berpikir kreatif.

Majid (2014:85), menyatakan bahwa pembelajaran tematik terpadu adalah sesuatu pendekatan pada pembelajaran yaitu dilakukan dengan cara dibuat-buat agar dikaitkan dengan berbagai situasi dan masalah yang masuk dalam intramata pelajaran (hanya satu muatan pelajaran) atau antar muatan pelajaran (berbagai muatan pelajaran). Trianto (2011:147), menyatakan bahwa pembelajaran tematik terpadu adalah pembelajaran yang menggunakan tema untuk mengaitkan beberapa mata pelajaran sehingga dapat memberikan pengalaman yang nyata pada peserta didik. Sedangkan Rusman (2017:254) berpendapat bahwa pembelajaran tematik merupakan model pembelajaran yang menggunakan pendekatan tematik dengan melibatkan beberapa mata pelajaran untuk menghasilkan pengalaman bermakna pada peserta didik.

Trianto (2010:118) menyatakan bahwa seorang guru harus ikut berpartisipasi dalam segala medan yang dihadapinya, termasuk menghadapi peserta didik yang memiliki kemampuan berbedabeda, sehingga dalam pembelajaran tematik memerlukan guru yang kreatif, baik dalam menyiapkan kegiatan belajar bagi anak serta juga dapat memilih kompetensi dari berbagai muatan pelajaran dan mengaturnya agar pembelajaran menjadi lebih bermakna, menarik, menyenangkan dan utuh serta guru harus berinovasi dan mempunyai keterampilan: Creativity and innovation, critical thinking and Problem Solving , communication, serta collaboration (Conklin, 2012:17). Dengan demikian peserta didik bukan hanya menerimanya saja atau, tidak hanya hafalan tetapi dapat mengembangkan pengetahuan berpikir kritis peserta didik dalam proses pembelajaran.

Susanto (2013:122), menyatakan bahwa berpikir kritis merupakan keterampilan berpikir tingkat tinggi, dimana mencakup menganalisa, mengetahui masalah dan pemecahan masalah, berkesimpulan dan mengevaluasi. Ahmatika (2015:395) mengatakan bahwa berpikir kritis adalah kemampuan berpikir tinggkat tinggi dimana suatu kemampuan yang begitu mendasar serta berfungsi efektif dalam masalah dan situasi pada setiap aspek kehidupan. Adnyana (2012:202) berpendapat bahwa keterampilan berpikir kritis disebut juga sebagai keahlian tingkat tinggi yang bisa membantu peserta didik melaksanakan analisis dengan cara mendapatkan fakta yang terjadi dan dapat memberikan argumen atau pendapat serta bisa membuat kesimpulan yang tepat

Syutaridho dan Turmudi (2013:189) menyebutkan indicator berpikir kritis ialah: (1) Focus; a) menyelidiki maksud dari problema yang di tandai menggunakan catatan-catatan khusus dalam buku catatannya. b) berfokus pada sebuah masalah atau sebuah point yang bisa diliat pada saat bertanya. Menanyakan sesuatu yang berhubungan dengan pendukun untuk mengumpulkan informasi tertentu. (2) Reasons; a) dapat menunjukan alasan dalam membuat keputusan strategi dalam menyeleseikan masalah. 
500 Perbedaan model pembelajaran problem solving dan discovery learning ditinjau dari keterampilan berpikir kritis peserta didik - Maklonia Meling Moto, Srigiarti

b) alasan yang bersangkutan dengan pengetahuan dan keyakinan yang ditunjukan dengan memberikan argumen dari suatu masalah hasil identifikasi maupun observasi. (3)Inference; a) dapat menyampaikan kesimpulan dengan menggunkan alasan yang logis. b) berani dalam menggunakan berbagai strategi untuk menyeleseikan masalah dengan tujuan mendapatkan solusi. (4) Situation; a) berhubungan dengan situasi yang artinya cara seseorang memandang masalah tersebut. b) dari sebuah konteks bisa memilih strategi yang akurat. (5)Clarity; menunjukkan contoh model lain dari sebuah masalah matematik atau bisa juga ditandai dengan melakukan pemisahan untuk menerangkan sesuatu. (6)Overview; a) Memandang bahwa solusi dari suatu strategi untuk menyeleseikan sebuah masalah memiliki alasan yang akurat. b) berkaitan dengan menyakinkan diri bahwa strategi yang di pakai sudah tepat dengan memperhatikan kembali pekerjaannya.

Hamdani (2010:84) menyebutkan ada banyak model pembelajaran yang dapat digunakan dalam pembelajaran yaitu model Pembelajaran Pemecahan Masalah (Problem Solving ), Role Playing, Pembelajaran Berbasis Masalah (PBM), Cooperative Script, Picture And Picture, Numbered Heads Together, Group Investigation, Jigsaw, Team Games Tournament (TGT), Student Teams-Achievement Divisions (STAD), Example non Example, Inquiry Learning, Discovery Learning. Berpijak dari banyak model pembelajaran yang dapat digunakan guru dalam pembelajaran, salah satunya model pembelajaran Problem Solving . Hamdani (2011:84) menyatakan bahwa model pembelajaran Problem Solving (pemecahan masalah) adalah suatu model yang cara penyediaan pelajaran dengan mendorong peserta didik agar menemukan dan memecahkan suatu masalah atau persoalan dalam rangka mencapai tujuan pengajaran. Wena (2009: 52) menyatakan bahwa metode Problem Solving adalah mengerjakan operasi procedural urutan tindakan, tahap demi tahap secara sistematis.

Selanjutnya, keberhasilan model pembelajaran Problem Solving dalam meningkatkan keterampilan berpikir kritis siswa ditunjukkan oleh hasil penelitian yang dilakukan oleh Tia Ristiasari, Bambang Priyono, Sri Sukaesih (2012:7), mengenai model pembelajaran Problem Solving dengan mind mapping terhadap kemampuan berpikir kritis siswa. Hasil menunjukkan peningkatan tes kemampuan berpikir kritis siswa kelas eksperimen sebesar 0,40 (sedang) sedangkan untuk kelas kontrol sebesar 0,23 (Rendah). Penelitian selanjutnya dilakukan oleh Anwar, Yusrizal dan Zulkarnaen Jalil (2017:20) yang menyatakan bahwa Problem Solving bisa meningkatkan ketrampilan berpikir kritis antara pretest dan posttest dengan hasil uji $\mathrm{t}$ diperoleh thitung >ttabel $(6,33>2,010)$ artinya terjadi perbedaan ketrampilan berpikir kritis yang signifikan antara kedua kelas.

Selain model pembelajaran Problem Solving, adapun juga model pembelajaran yang dapat meningkatkan berpikir kritis peserta didik yaitu model pembelajran Discovery Learning. Direktorat Pembinaan Sekolah Dasar (2016:60) model Discovery learning merupakan tahap pembelajaran dengan mengaitkan peserta didik agar mengatur atau menyusun sendiri bahan latihan melalui proses suatu rancangan atau dasar yang tidak dipahami peserta didik. Agus N. Cahyo (2013:100) menyatakan model Discovery learning ialah metode mengajar yang dapat menyusun pegajaran sedemikian macam sehingga peserta didik mendapatkan pengetahuan yang sebelumnya belum diketahui peserta didik melalui pemberitahuan, namun dapat menemukan sendiri.

Kerberhasilan model model pembelajaran Discovery learning juga ditunjukkan dari hasil penelitian Penelitian dari Agustina Merry, Arwin 
501 Perbedaan model pembelajaran problem solving dan discovery learning ditinjau dari keterampilan berpikir kritis peserta didik - Maklonia Meling Moto, Srigiarti

Achmad, Berti Yolida (2019:8-9), menunjukkan bahwa model pembelajaran Discovery learning berpengaruh terhadap kemampuan berpikir kritis dan hasil belajar siswa dengan persentase kemampuan berpikir kritis kelas eksperimen $(80,5 \%)$ lebih tinggi dibandingkan kelas kontrol $(61,9 \%)$. Kemudian, hasil belajar diperoleh dari $N$ Gain pada kelas eksperimen (65\%) juga lebih tinggi dibandingkan kelas kontrol (50\%). Selanjutnya Yusmanto dan Tatang Herman (2016) melakukan penelitian mengenai pengaruh penerapan model pembelajaran Discovery learning terhadap peningkatan kemampuan berpikir kritis matematis dan self confidence siswa kelas $\mathrm{v}$ sekolah dasar. Hasil penelitian menunjukkan bahwa pembelajaran matematika dengan model discovery learning dapat meningkatkan kemampuan berpikir kritis matematis selftconfidence matematika siswa di kelas eksperimen yang menggunakan model pdiscovery learning lebih baik dibandingkan dengan kelas kontrol yang menggunakan pembelajaran langsung.

Berdasarkan pengertian dari model Problem Solving dan Discovery learning serta hasil penelitian yang telah dilakukan terdahulu maka dapat disimpulkan bahwa kedua model pembelajaran tersebut terbukti dapat meningkatkan keterampilan berpikir kritis peserta didik, Berpijak pada keefektifan penerapan kedua model pembelajaran Problem Solving dan Discovery Learning dari proses pembelajaran dan dalam muatan pelajaran sehingga menimbulkan keraguraguan bagi peneliti untuk membuktikan keefektifan kedua model ini, maka penulis melakukan penelitian dengan berdasarkan latar belakang yang dirumuskan masalahnya yaitu apakah terdapat perbedaan model pembelajaran Problem Solving dan Discovery learning ditinjau dari keterampilan berpikir kritis peserta didik kelas 4 dalam pembelajaran tematik.

\section{METODE}

Jenis penelitian ini adalah eksperimen semu (Quasi Eksperimental Research). Dengan desain penelitian menggunakan desain statis dengan perbandingan grup statis. Teknik pengambilan sampel yang di gunakan dalam penelitian ini adalah purposive sampling teknik penentuan sampel dengan pertimbangan tertentu (sugiyono 2013:68). Dengan jumlah sampel 51 peserta didik, yaitu 26 peserta didik kelas eksperimen dan 25 peserta didik sebagai kelas kontrol.

Teknik pengumpulan data yang digunakan adalah tes dan non tes. Instrument pengumpulan data yang dipakai adalah lembar observasi kegiatan peserta didik dan kegiatan guru dalam menjalankan model pembelajaran Problem Solving dan Discovery Learning dana lembar soal posttest dalam bentuk isian . Observasi dalam penelitian ini akan dilaksana oleh guru kelas 4 SD agar dapat mengetahui ketercapaian guru dan peserta didik pada saat menerapkan model pembelajaran Problem Solving dan Discovery Learning. Soal yang digunakan sebagai soal menguji tingkat kemampuan peserta didik adalah soal yang telah divaliditas dan reliabilitas. Dari 20 soal yang dibuat oleh peneliti terdapat 17 soal yang valid dan memiliki nilai reliabilitas 0,873 yang artinya berarti realibilitas tes sangat tinggi. Teknik analisis data menggunakan uji normalitas, uji homogenitas dan uji hipotesis menggunakan uji Independent Samples Test.

\section{HASIL DAN PEMBAHASAN}

Penelitian ini bertujuan untuk mengetahui perbedaan model pembelajaran Problem Solving dan Discovery learning ditinjau dari keterampilan berpikir kritis peserta didik kelas 4 SD dalam pembelajaran tematik. Data penelitian ini diperoleh melalui proses pembelajaran pada kelas eksperimen dan kelas kontrol yang 
502 Perbedaan model pembelajaran problem solving dan discovery learning ditinjau dari keterampilan berpikir kritis peserta didik - Maklonia Meling Moto, Srigiarti

dilaksanakan sesuai dengan sintak Problem penelitian menunjukkan perbandingan dari hasil Solving dan Discovery Learning. Kedua kelas ini keterampilan berpikir kritis dapat dilihat pada tabel diajarkan dengan materi yang sama tetapi dengan 1 berikut: perlakuan atau treatment yang berbeda. Hasil

Tabel 1 Hasil Kemampuan Berpikir Kritis Siswa

\begin{tabular}{cccccccc}
\hline Kelas & N & $\begin{array}{c}\text { Skor } \\
\text { Ideal }\end{array}$ & $\begin{array}{c}\text { Skor } \\
\text { Min }\end{array}$ & $\begin{array}{c}\text { Skor } \\
\text { Max }\end{array}$ & $\begin{array}{c}\text { Rata- } \\
\text { rata }\end{array}$ & $\begin{array}{c}\text { Presentase } \\
\text { (\%) }\end{array}$ \\
\hline \multirow{2}{*}{ Post test } & $\begin{array}{c}\text { Kelas } \\
\text { Eksperimen }\end{array}$ & 25 & 100 & 50 & 85 & 61,32 & $61 \%$ \\
\cline { 2 - 7 } & $\begin{array}{c}\text { Kelas } \\
\text { Kontrol }\end{array}$ & 26 & 100 & 50 & 90 & 66,85 & $67 \%$ \\
\hline
\end{tabular}

berdistribusi normal. Maka diputuskan apabila

Hasil analisis keterampilan berpikir kritis pada kelompok eksperimen Discovery learning dengan menggunakan model pembelajaran memperoleh nilai rata-rata sebesar 61,32, adapun nilai maksimal yang diperoleh yaitu 85 dan nilai minimal yaitu 50. Pada kelompok kelas kontrol dengan menggunakan model pembelajaran Problem Solving memperoleh nilai rata-rata 66,85, nilai maksimal 90 dan nilai minimal 50.

Uji prasyarat eksperimen dilakukan menggunakan uji normalitas dan uji homogenitas data. Uji normalitas. Hasil uji normalitas pada keterampilan berpikir kritis pada pembelajaran tematik untuk kelas eksperimen memperoleh hasil 0,002 sedangkan pada kelas kontrol memperoleh hasil 0,005. Berdasarkan rumusan hipotesis Ho adalah sebuah sampel yang berasl dari populasi signifikasi $<0,05$ Ho di tolak. Karena nilai signifikasi pada kelas eksperimen 0,002 <0,05 dan kelas kontrol 0,005 > 0,05 maka Ho ditolak Ha diterima. Kelompok kelas eksperimen dan kontrol berasal dari populasi yang berdistribusi tidak normal.

Selanjutnya uji homogenitas dilakukan untuk mengetahui varian dari kedua kelompok homongen atau tidak homogen. Data dapat dikatakan homogen apabila nilai signifikan > 0,05. Dari hasil uji homogenitas dari kedua kelompok eksperimen diperoleh hasil sebesar 0,098. Oleh karena itu, nilai signifikasi 0,098>0,50 yang berarti kelompok eksperimen dan kelompok kontrol adalah homogen. Hasil uji hipotesis dilakukan menggunakan uji independent sampel TTest hasilnya dapat dilihat pada tabel 2

\begin{tabular}{|c|c|c|c|c|c|c|c|c|c|}
\hline \multicolumn{10}{|c|}{$\begin{array}{l}\text { Tabel 2. Hasil Uji Hipotesis Uji T } \\
\text { Independent Samples Test }\end{array}$} \\
\hline & \multicolumn{2}{|c|}{$\begin{array}{l}\text { Levene's Test } \\
\text { for Equality of } \\
\text { Variances }\end{array}$} & \multicolumn{7}{|c|}{ t-test for Equality of Means } \\
\hline & \multirow[b]{2}{*}{$\mathrm{F}$} & \multirow[b]{2}{*}{ Sig. } & \multirow[b]{2}{*}{$\mathrm{t}$} & \multirow[b]{2}{*}{ df } & \multirow{2}{*}{$\begin{array}{l}\text { Sig. }(2- \\
\text { tailed) }\end{array}$} & \multirow{2}{*}{$\begin{array}{l}\text { Mean } \\
\text { Differe } \\
\text { nce }\end{array}$} & \multirow{2}{*}{$\begin{array}{c}\text { Std. } \\
\text { Error } \\
\text { Differe } \\
\text { nce }\end{array}$} & \multicolumn{2}{|c|}{$\begin{array}{c}95 \% \text { Confidence } \\
\text { Interval of the } \\
\text { Difference }\end{array}$} \\
\hline & & & & & & & & Lower & Upper \\
\hline $\begin{array}{ll}\mathrm{Ha} & \text { Equal } \\
\text { sil } & \text { variances } \\
& \text { assumed }\end{array}$ & 2.589 & .114 & $\begin{array}{r}- \\
2.33 \\
3\end{array}$ & 49 & .024 & -5.526 & 2.368 & -10.285 & -.767 \\
\hline $\begin{array}{l}\text { Equal } \\
\text { variances not } \\
\text { assumed }\end{array}$ & & & $\begin{array}{r}- \\
2.34 \\
4\end{array}$ & $\begin{array}{r}47.3 \\
42\end{array}$ & .023 & -5.526 & 2.358 & -10.268 & -.784 \\
\hline
\end{tabular}


503 Perbedaan model pembelajaran problem solving dan discovery learning ditinjau dari keterampilan berpikir kritis peserta didik - Maklonia Meling Moto, Srigiarti

Berdasarkan hasil uji $\mathrm{T}$ pada tabel diatas dapat diketahui bahwa uji hipotesis dengan teknik independent samples $T$-test yang menunjukan nilai signifikansi pada $\mathrm{F}$ sebesar 2,589 dengan probabilitas sig (2-tailed) sebesar 0,024. Hal ini berarti Ho ditolak dan $\mathrm{Ha}$ diterima, dikarenakan nilai signifikansi sebesar $0,024<0,050$ sehingga dinyatakan terdapat perbedaan yang signifikan antara penggunaan model Problem Solving dan Discovery learning ditinjau dari keterampilan berpikir kritis pesrta didik kelas 4 pada pembelajaran tematik.

Temuan yang di dapat peneliti yaitu berpikir kritis peserta didik dalam penggunan model pembelajaran Problem Solving lebih unggul secara signifikan dibandingkan model pembelajaran Discovery leraning pada pembelajaran tematik kelas 4. Sejalan dengan hasil temuan dari Anwar, Yusrizal dan Zulkarnaen Jalil (2017) penelitian tentang implementasi strategi Problem Solving dengan menggunakan metode eksperimen untuk meningkatkan minat dan keterampilan berpikir kritis siswa di Man Ganpura pada materi gerak harmoni. Penemuan kedua yang dilakukan Mufti Ali, dan Siska Amalia (2018), mengenai pengaruh model pembelajaran Problem Solving terhadap berpikir kritis peserta didik pada sub konsep pencemaran lingkungan. Selanjutnya oleh Resti Rima Safitri, Atrup, dan Guruh Sukma Hanggara (2018:5), mengenai Problem Solving dalam meningkatkan kemampuan berpikir kritis siswa. Penelitian selanjutnya dilakukan oleh Tia Ristiasari, Bambang Priyono, Sri Sukaesih (2012:7), mengenai model pembelajaran Problem Solving dengan mind mapping terhadap kemampuan berpikir kritis siswa.

\section{SIMPULAN}

Simpulan penelitian yaitu terdapat pengaruh yang signifikan terhadap kemampuan berpikir kritis peserta didik melalui penerapan model Problem Solving . Hal tersebut ditunjukkan bahwa kemampuan berpikir kritis peserta didik kelas 4 SD pada pembelajaran tematik lebih tinggi dibandingkan dengan peserta didik yang diberikan perlakuan model lain yaitu Discovery Learning dengan $F$ hitung sebesar $2.589 \mathrm{p}=0,024$ $(0,024<0,05)$

Saran peneliti yang pertama bagi pendidik atau guru melalui penelitian ini apabila hendak menerapkan model pembelajaran Problem Solving akan lebih bak jika merencakanan pembelajaran dengan persiapan yang matang. Saran peneliti yang kedua, bagi peneliti lain diharapkan melalui penelitian ini dapat menjadi salah satu referensi namun apabila hendak menerapkan model pembelajaran yang sama akan lebih baik jika menggunakan media pembelajaran sehingga lebih inovatif.

\section{DAFTAR PUSTAKA}

Adnyana, Gede Putra. 2012. "Konsep Siswa Pada Model Siklus Belajar." Jurnal Pendidikan Dan Pengajaran (3): 201-9.

Agustina, Merry, Arwin Achmad, and Berti Yolida. 2019. "Pengaruh Model Discovery learning Terhadap Kemampuan Berpikir Kritis Dan Hasil Belajar Siswa." Journal of Chemical Information and Modeling 53(9): 1689-99.

Ahmatika, Deti. 2017. "Peningkatan Kemampuan Berpikir Kritis Siswa Dengan Pendekatan Inquiry/Discovery.” Euclid 3(1): 394-403.

Amalia2), Mufti Ali1) Siska. 2018. "Pengaruh Model Pembelajaran Problem Solving terhadap Berpikir Kritis Peserta Didik pada Sub Konsep Pencemaran Lingkungan." Jurnal Bio Educatio 3(2): 1-6.

Anwar, Yuzrizal, and Zulkarnaen Jalil. 2017. "Implementasi Strategi Problem Solving Dengan Menggunakan Metode Eksperimen Untuk Meningkatkan Minat Dan Ketrampilan Berpikir Kritis Siswa Di Man Gandapura Pada Materi Gerak Harmonic." Jurnal IPA \& Pembelajaran IPA 3 (2): 16-25

Abdul, Majid. 2014. "Pembelajaran Tematik Terpadu.” Bandung: Remaja Rosdakarya 
504 Perbedaan model pembelajaran problem solving dan discovery learning ditinjau dari keterampilan berpikir kritis peserta didik - Maklonia Meling Moto, Srigiarti

Agus, Cahyo Nugroho. 2013. "Panduan Aplikasi Teori-Teeori Belajar Mengajar Teraktual dan Terpopuler." yogjakarta: DIVA Press.

Conklin, Wendy. 2012. "Higher-order thinking skills to develop 21st century learners." Huntingon Beach: Shell Educationl Publishing, Inc.

Direktorat Pembina Sekola Dasar. 2016.“Paduan Teknis Pembelajaran di Sekola Dasar.” Jakarta. Kemendikbud.

Hamdani. 2010. "Strategi Belajar Mengajar." Bandung: Pustaka Setia

Hamdani. 2011. "Strategi Belajar Mengajar." Bandung: CV. Pustaka Setia

Permendikbud Nomor 65 Tahun 2013 tentang Standar Isi Pendidikan Dasar dan Menengah." Jakarta: Kemdikbud

Ristiasari, Tia, Bambang Priyono, and Sri Sukaesih. 2012. "Model Pembelajaran Problem Solving Dengan Mind Mapping Terhadap Kemampuan Berpikir Kritis Siswa." Journal of Biology Education 1(3).

Rusman. 2017. “Model-Model Pembelajaran (Mengembangkan profesionalitas Guru)." jakarta: Rajawali Press.

Safitri, Resti Rima, Atrup Atrup, and Guruh Sukma Hanggara. 2018. "Problem Solving Dalam Meningkatkan Kemampuan Berpikir Kritis Siswa SMK." Nusantara of Research : Jurnal Hasil-hasil Penelitian Universitas Nusantara PGRI Kediri 5(2): 83-88.

Sugiyono. 2013. "Metode Penelitian Pendidikan Pendekatan Kuantitatif, Kualitatif, dan $R \& D$." Bandung: Alfabeta.

Susanto, A. 2013. “ Teori Belajar dan Pembelajaran di Sekolah Dasar." Jakarta: Kencana Prenadamedia Group.

Syutaridho, and Dedi Turmudi 2013. "Pendekatan Contextual Teaching And Learning Sebagai Alternatif Melatih Berpikir kritis. Prosiding Seminar nasional Universitas Muhammadiyah Metro. " Hal 179-184. Tanggal 16 November 2011

Trianto. 2011. "Desain Pengembangan pembelajaran tematik bagi anak usia dini TK/RA dan anak usia kelas awal SD/MI." Jakarta: kencana.

Trianto. 2010. "Model Pembelajaran Terpadu" Jakarta: Bumi Aksara

Tusmanto. and Tatang . Herman. 2016. "Pengaruh Penerapan Model Pembelajaran Discovery Learning Terhadap Peningkatan Kemampuan Berpikir Kritis Matematis Dan Self Confidence Siswa Kelas V
Sekolah Dasar. " Eduhumaniora Jurnal Pendidikan Dasar 7(2): 140-151

Wena, Made. 2009. "Strategi Pembelajaran Inovatif Kontemporer. Jakarta: Bumi 